\title{
DESENVOLVIMENTO DE OBJETOS DE APRENDIZAGEM PARA AVEAS INCLUSIVOS A PARTIR DE NARRATIVAS EM HIPERMÍDIA: UM ESTUDO DE TRANSPOSIÇÃO
}

\section{DEVELOPMENT OF LEARNING OBJECTS FOR INCLUSIVE LMS FROM HYPERMEDIA NARRATIVES: A TRANSPOSITION STUDY}

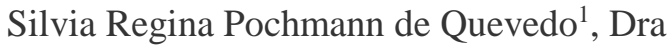 \\ Luiz AM Palazzo ${ }^{2}$, Dr. \\ Luiz Henrique Longhi Rossi ${ }^{3}$, Dr. \\ Tarcisio Vanzin ${ }^{4}$, Dr. \\ Doris Roncarelli ${ }^{5}$, Dra \\ Universidade Federal de Santa Catarina \\ silviareginaquevedo@gmail.com \\ Universidade Federal de Santa Catarina \\ Luiz.palazzo@gmail.com \\ Universidade Federal do Rio Grande do Sul \\ Ih.rossi@cognitivabrasil.com.br
Universidade Federal de Santa Catarina tvanzin@gmail.com \\ Universidade Federal de Santa Catarina \\ dorisroncarelli@gmail.com
}

Palavras-chave: Objetos de Aprendizagem, Metadados, Padrões de Desenvolvimento

\begin{abstract}
Este artigo apresenta o desenvolvimento de Objetos de Aprendizagem (OAS) originários de narrativas em hipermídia ao Ambiente Virtual de Ensino Aprendizagem (AVEA) WebGD Acessível para o ensino de Geometria Descritiva na perspectiva da acessibilidade e inclusão. Implementado na plataforma Moodle, adaptada especialmente para alunos com deficiência auditiva e visual, o AVEA foi desenvolvido por pesquisadores da Universidade Federal de Santa Catarina (UFSC), com o armazenamento dos objetos realizado em parceria com a Universidade Federal do Rio Grande do Sul (UFRGS). A partir de narrativas em diferentes gêneros foram desenvolvidos 17 OAs pelo padrão brasileiro de metadados OBAA (Objetos de Aprendizagem Baseados em Agentes). Os OAs foram modelados de acordo com as propriedades mais importantes como a modularidade, interoperabilidade, recuperação e reusabilidade. Este estudo apresenta a transposição das narrativas implementadas originalmente no Moodle para OAs e como as propriedades destes puderam ser alcançadas.
\end{abstract}




\section{$16^{\circ}$ \\ ERGODESIGN USIHC CINAHPA}

$16^{\circ}$ Ergodesign - Congresso Internacional de Ergonomia e Usabilidade de Interfaces Humano Tecnológica: Produto, Informações Ambientes Construídos e Transporte

$16^{\circ}$ USIHC - Congresso Internacional de Ergonomia e Usabilidade de Interfaces Humano Computador

CINAHPA | 2017 - Congresso Internacional de Ambientes Hipermídia para Aprendizagem.

\section{Keywords: Learning Objects, Metadata, Developing Patterns}

This article presents the development of Learning Objects $(L O)$ originating from hypermedia narratives developed to the Learning Management Systems (LMS) WebGD Acessivel for teaching Descriptive Geometry with the perspective of accessibility and inclusion. Implemented in the Moodle platform, specially adapted for students with hearing or visual impairments, the LMS was developed by researchers from the Federal University of Santa Catarina (UFSC), with the storage of objects carried out in partnership with the Federal University of Rio Grande do Sul (UFRGS). Based on narratives in diferente styles, 17 LO were developed by the Brazilian OBAA metadata standard (Agents-Based Learning Objects). The LO were modeled according to most important properties such as modularity, interoperability, recovery and reusability. This study presents the transposition of the narratives originally implemented in Moodle for $L O$ and how their properties could be reached.

\section{Introdução}

O desenvolvimento de Objetos de Aprendizagem (OAs) veio para contemplar uma necessidade colocada especialmente pelo segmento de Educação a Distância (EAD). À medida que os programas de EAD acompanham o crescimento tecnológico e multiplicam-se em todos os níveis, requerem, ao mesmo tempo, conteúdos organizados em domínios e apoiados por sistemas gerenciadores e Ambientes Virtuais de Ensino Aprendizagem (AVEAs) [MACEDO, 2013].

Essa espécie de 'proliferação' tecnológica fez com que um novo enfoque para o conteúdo em EAD passasse a ser valorizado, com a ideia de que os temas educacionais pudessem ser oferecidos de forma modular, menores, interativos, com capacidade de reutilização em vários contextos e, claro, digitais [SANTOS, FLORES E TAROUCO, 2007]. Desse modo, os OAs surgiram com o objetivo de localizar e reutilizar os conteúdos educacionais disponíveis na web [MACEDO, 2013].

Segundo o IEEE [Institute of Electrical and Electronic Engineering, 2016], um OA pode ser qualquer entidade digital, texto, filme, animação, conteúdo instrucional ou uma composição desses organismos em objetos maiores, com o propósito educacional definido. Sua padronização e personalização recomendam o uso de sistemas hipermídia, o que permite utilização simultânea de mídias e navegação não linear. Agregue-se a isso o ponto de vista da inclusão, e as narrativas em hipermídia adquirem importância ampliada pelo prisma da diversidade.

O WebGD Acessível nasceu inclusivo para alunos com deficiência em visão e audição. Seu objetivo foi constituir-se como AVEA na área de Geometria Descritiva (GD), disciplina com alto grau de dificuldade, em especial aos jovens que se encontram em fase de graduação. Sendo a GD um desafio para alunos sem deficiência, o ambiente ganhou amplitude por buscar garantir esse conhecimento também a alunos que requerem atendimento especial. Inicialmente, dada a exigência de aglutinar-se várias áreas - Matemática, Ciência da Computação, Comunicação Social, Psicologia, Pedagogia e Design, uma equipe de pesquisadores da Universidade Federal de Santa Catarina (UFSC) buscou construir o ambiente de modo interdisciplinar. A pesquisa começou com profunda investigação sobre cada deficiência sensorial e a forma como esses públicos-alvos aprendem, para depois à elaboração de mapas mentais, adaptação do Moodle para garantir acessibilidade, configurações do sistema e desenvolvimento do conteúdo.

O conteúdo do WebGD Acessível foi desenvolvido na Língua Portuguesa, nas linguagens escrita e oral, e na Língua Brasileira de Sinais (Libras) em vídeo. O AVEA apresentase constituído por narrativas em hipermídia nos gêneros História em Quadrinhos (HQ), Contos (literários), e Narrativa Dissertativa (texto argumentativo). A Infografia, mesclando texto e imagens, aparece com o requinte de oferecer a língua de sinais também escrita, a signwritting, 


\section{$16^{\circ}$ \\ ERGODESIGN USIHC CINAHPA}

$16^{\circ}$ Ergodesign - Congresso Internacional de Ergonomia e Usabilidade de Interfaces Humano Tecnológica: Produto, Informações Ambientes Construídos e Transporte

$16^{\circ}$ USIHC - Congresso Internacional de Ergonomia e Usabilidade de Interfaces Humano Computador

CINAHPA | 2017 - Congresso Internacional de Ambientes Hipermídia para Aprendizagem. incipiente mesmo para os surdos.

Chegar aos OAs contemplou a parte final de implementação do projeto. A pergunta era como transpor as narrativas em hipermídia a fim de que o conteúdo pudesse ser armazenado, recuperado e reutilizado por mais pessoas, em especial docentes, que precisam se municiar de ferramentas, conhecimento e criatividade no planejamento de suas aulas. $\mathrm{O}$ trabalho envolveu a parceria de pesquisadores da Universidade Federal do Rio Grande do Sul (UFRGS) para a elaboração dos OAs e sua disponibilização em repositório.

\section{Método}

Os Objetos de Aprendizagem foram desenvolvidos em dois níveis de agregação, considerando-se o conteúdo pedagógico e a descrição dos metadados. Todos eles foram modelados levando-se em conta as propriedades mais importantes de OAs como a modularidade, interoperabilidade e recuperação, mas, principalmente, a reusabilidade.

A modularidade descreve o grau de separação e consequente recombinação dos componentes do OA. Interoperabilidade é a capacidade de operar em plataformas heterogêneas. A recuperação está relacionada à capacidade de poder ser encontrado em função de sua descrição de propriedades e funcionalidades, por fim a reusabilidade permite sua utilização em qualquer momento e por diferentes aplicações.

\subsection{Reusabilidade}

Um OA modulável aumenta sua capacidade de reusabilidade, uma vez que poderão ser reutilizadas partes menores desse material. Para isso todos os objetos de aprendizagem do projeto foram divididos em partes, o que permite usar, além do material completo, frações menores de conteúdo.

Para que os objetos possam ser recuperáveis é importante que sejam catalogados de forma correta, a fim de que uma plataforma de busca seja capaz de resolver consultas específicas. $\mathrm{O}$ processo de catalogação passou pela escolha de um padrão de metadados e, posteriormente, pela definição de um repositório, para que os OAs do WebGD Acessível pudessem ter suas características e conteúdos descritos e recuperados em qualquer momento.

\subsection{Metadados}

Um OA é composto basicamente por duas partes: conteúdo pedagógico e metadados [POMERANTZ, 2016]. Mais do que o significado da palavra leva a entender, metadados (dados sobre dados) são elementos utilizados como descrição do conteúdo [POMERANTZ, 2016]. No caso educacional, dizem respeito a dados que descrevem um OA. Representam informações gerais como, por exemplo, título, autor, descrição, data de criação etc. Também podem oferecer outras informações, como para quem determinado objeto de aprendizagem foi desenvolvido, idade do público-alvo, tempo de duração (caso se trate de um vídeo), relações entre os OAs e muito mais.

\subsubsection{Padrão de Metadados}

Para que as informações descritas nos metadados possam ser interpretadas é necessário que estes sejam todos representados no mesmo padrão, de modo que os dados possam ser absorvidos da mesma forma. Existem diversos padrões de metadados que podem ser separados segundo suas características, de acordo com o propósito de cada objeto.

Há, por exemplo, os metadados para humanos, como a ficha catalográfica de um livro ou a tabela nutricional de algum alimento; metadados para máquinas ou híbridos, como o padrão HTML, que além de fornecer os dados para que os navegadores exibam corretamente a página, torna possível oferecer informações para seres humanos. Os padrões de metadados educacionais normalmente são híbridos e representados em XML.

Entre os padrões de metadados mais utilizados cita-se o Dublin Core, que oferece um núcleo 


\section{$16^{\circ}$ \\ ERGODESIGN USIHC CINAHPA}

comum para metadados, servindo para representar todo tipo de material digital e, portanto, não específico. Uma extensão para uso educacional do Dublin Core é o Learning Object Metadata (LOM), criado pelo já referido IEEE (Institute of Electrical and Electronic Engineers), instituição internacional e referência nessa área de conhecimento.

O LOM faz uso do conceito de hierarquia para seus metadados e, com isso, não somente organiza as informações sobre os OA como também evita sua duplicação. No LOM há um conjunto total de 59 metadados separados em nove categorias: geral, ciclo de vida, meta metadados, técnicos, educacionais, direitos, relações, anotações e classificação. Cada conjunto tem seus metadados específicos. O padrão escolhido para o repositório do conteúdo do WebGD Acessível foi o padrão OBAA (Objetos de Aprendizagem Baseados em Agentes). Concebido por pesquisadores da Universidade Federal do Rio Grande do Sul (UFRGS) em 2008, o OBAA fundamenta-se no padrão LOM e consiste em uma especificação brasileira para Objetos de Aprendizagem $16^{\circ}$ Ergodesign - Congresso Internacional de Ergonomia e Usabilidade de Interfaces Humano Tecnológica: Produto, Informações Ambientes Construídos e Transporte

$16^{\circ}$ USIHC - Congresso Internacional de Ergonomia e Usabilidade de Interfaces Humano Computador

CINAHPA | 2017 - Congresso Internacional de Ambientes Hipermídia para Aprendizagem.
[VICARI, 2010].

O OBAA tem como base a proposta inicial do IEEE-LOM, pois algumas classes de seus metadados foram importadas (geral, ciclo de vida, meta metadados, direitos, anotações e classificação,). No entanto, o grupo sobre especificações técnicas e educacionais foi modificado, mantendo totalmente a compatibilidade.

O OBAA introduziu a criação de dois novos grupos: acessibilidade e tabela de segmentação. Com isso, o OBAA totaliza 108 metadados para descrição dos materiais educacionais.

Constituindo-se como uma extensão do LOM, é possível dizer que o conjunto de dados do LOM está contido no conjunto de dados do OBAA, porém o contrário não é verdadeiro.

A Figura 1 demonstra um exemplo da configuração de metadados em OBAA de um dos contos transpostos ao novo formato. Ela oferece dados cujo padrão se repetiu em toda a transposição, como informações gerais do $\mathrm{AO}$, palavras-chaves utilizadas, identificador, ciclo de vida, contribuinte, direitos (no caso, direito autoral) e o tipo de interação esperada.

\section{OOognik

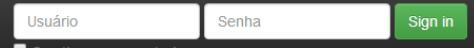

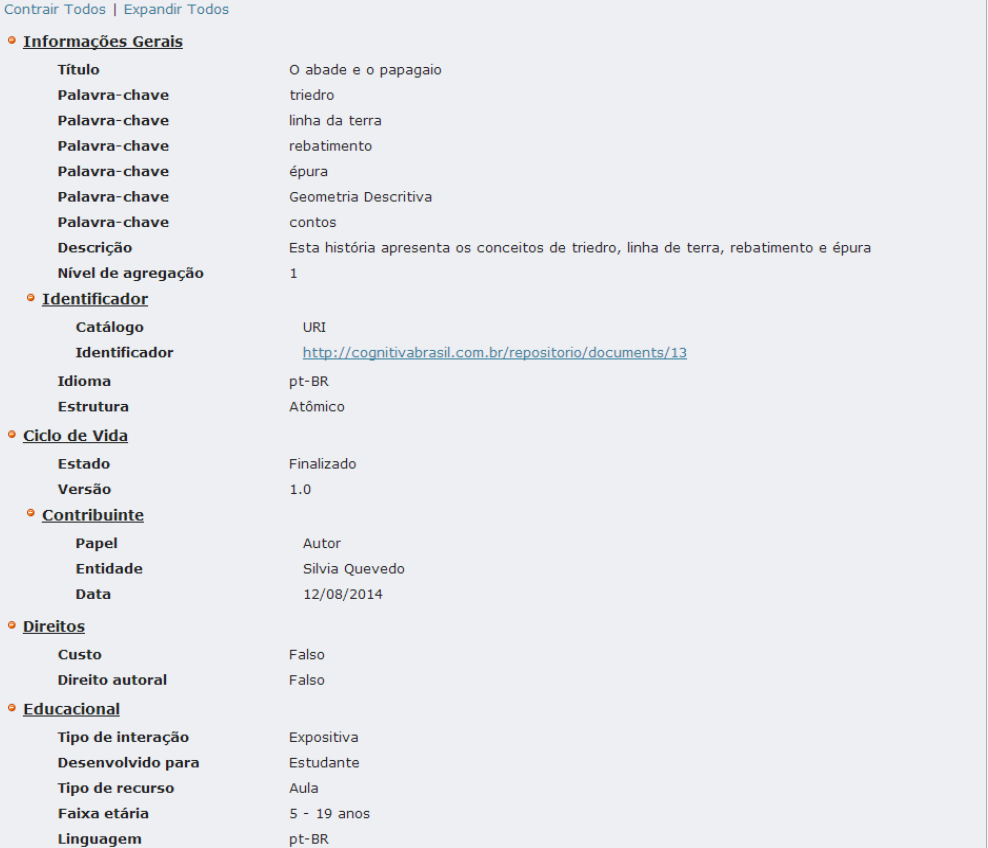




\section{$16^{\circ}$ \\ ERGODESIGN USIHC CINAHPA}

$16^{\circ}$ Ergodesign - Congresso Internacional de Ergonomia e Usabilidade de Interfaces Humano Tecnológica: Produto, Informações Ambientes Construídos e Transporte

$16^{\circ}$ USIHC - Congresso Internacional de Ergonomia e Usabilidade de Interfaces Humano Computador

CINAHPA | 2017 - Congresso Internacional de Ambientes Hipermídia para Aprendizagem.

Figura 1: Metadados do conto $\mathrm{O}$ abade e o papagaio em OBAA

Fonte: Cognitiva Brasil, 2014

Os metadados de acessibilidade foram originados a partir do padrão IMS (Institute Management Systems) e compreendem a criação de versões alternativas para os OAs originais, qualificando a catalogação de alternativas para informações visuais, textuais ou sonoras. Todo o padrão está documentado no seu site ${ }^{1}$.

\subsection{Repositório e reusabilidade}

O Repositório Educacional é um software onde os OAs são armazenados e catalogados, normalmente em um formato web, para que se possa disponibilizar o acesso de seu conteúdo. $\mathrm{O}$ armazenamento dos objetos do WebGD Acessível foi obtido em parceria com a UFRGS, e o repositório disponibilizado foi o Cognix. No repositório Cognix os OAs aparecem de modo independente e isolado, como objetos únicos a serem utilizados. Todo o material armazenado foi disponibilizado à Federação Educa Brasil ${ }^{2}$, um portal de agregação de objetos educacionais descrito em Rossi (2012). Uma vez no repositório, os OAs do WebGD Acessível estão disponíveis para reuso. Reusabilidade diz respeito à capacidade de um objeto de ser reutilizado, no mesmo ou em outro contexto, com fácil adaptação. Um objeto é mais reutilizável quando é modular, interoperável e recuperável.

\section{Resultados}

Foram desenvolvidos 17 Objetos de Aprendizagem para o AVEA WebGD Acessível, apresentados em três tipos de estrutura: os objetos atômicos, relacionados a partes menores, que não fazem relações a outros OAs; os objetos em rede, como a narrativa principal da HQ, que faz relações a outros OAs, sendo esse tipo bem característico de material com hiperlinks; e os objetos de coleção, como os contos, todos

\footnotetext{
${ }^{1}$ http://portalobaa.org

${ }^{2}$ http://feb.ufrgs.br/feb
}

independentes e, ao mesmo tempo, agregados em um OA principal.

A primeira narrativa a ser trabalhada foi a $\mathrm{HQ}$, que apresenta, na Língua Portuguesa escrita, a história de Zeca e Suzi. ${ }^{3}$ Zeca é um menino tímido, apaixonado, que espera conquistar a amada construindo uma casa para sua cachorrinha com base nos conhecimentos de GD aprendidos em aula.

Os quadrinhos com hiperlinks foram separados para que cada parte desse material pudesse ser utilizada ou referenciada de forma independente (Figura 2).

\footnotetext{
${ }^{3}$ As figuras reproduzidas neste estudo exemplificam
os OAs e não, necessariamente, seu conteúdo, por

${ }^{3}$ As figuras reproduzidas neste estudo exemplificam
os OAs e não, necessariamente, seu conteúdo, por

${ }^{3}$ As figuras reproduzidas neste estudo exemplificam
os OAs e não, necessariamente, seu conteúdo, por
este motivo a fonte das ilustrações é atribuída à Cognitiva Brasil, responsável pelo trabalho.
}

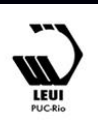




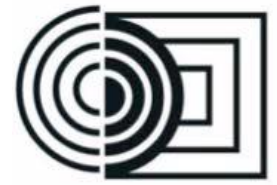

$16^{\circ}$ Ergodesign - Congresso Internacional de Ergonomia e Usabilidade de Interfaces Humano Tecnológica: Produto, Informações Ambientes Construídos e Transporte

$16^{\circ}$ USIHC - Congresso Internacional de Ergonomia e Usabilidade de Interfaces Humano Computador

CINAHPA | 2017 - Congresso Internacional de Ambientes Hipermídia para Aprendizagem.

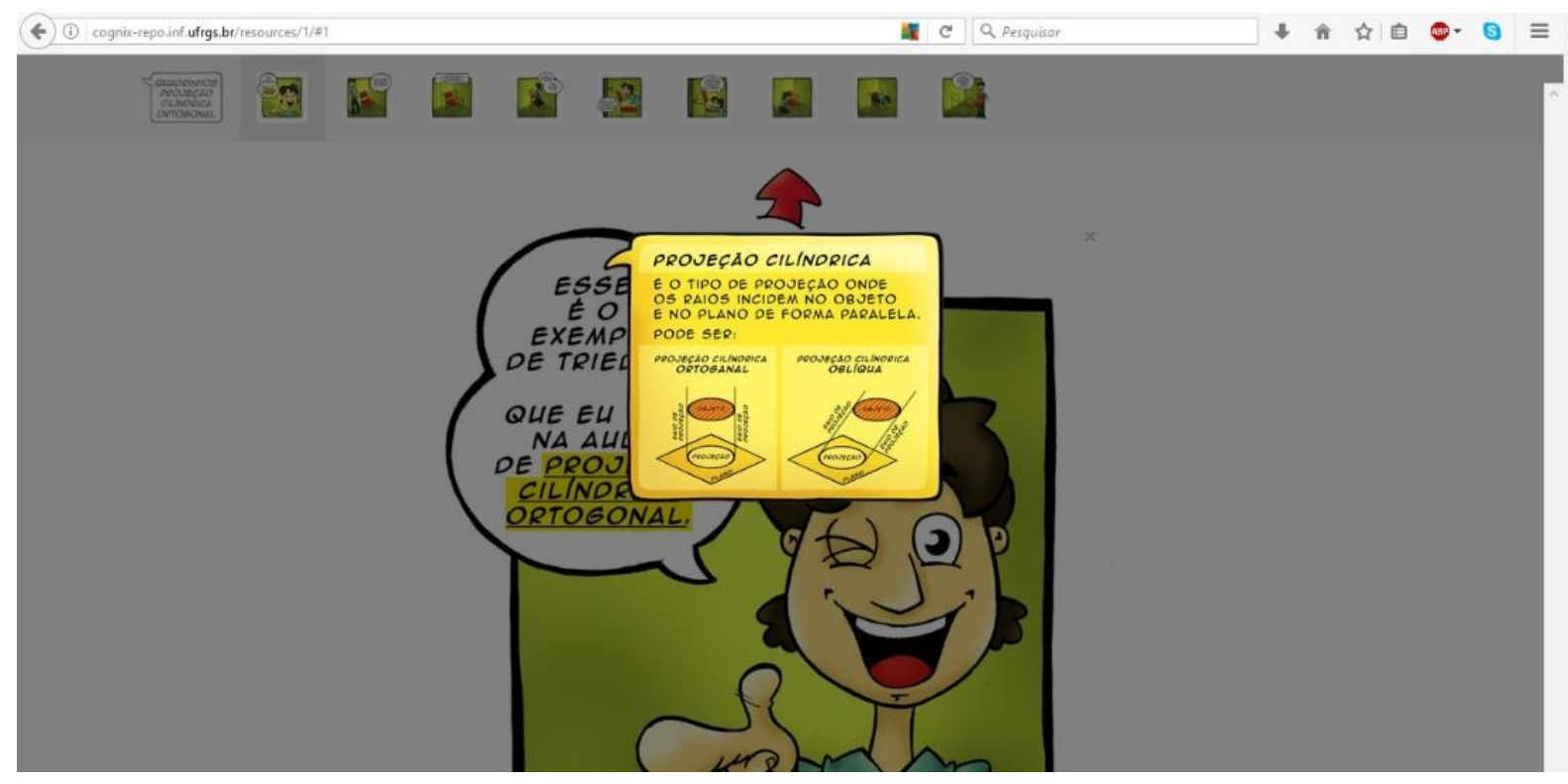

Figura 2: OA de quadrinho, com hiperlink, que não faz parte da história principal Fonte: Cognitiva Brasil, 2014

Isso deu agilidade à navegação, que dispensou longos minutos de espera para o download da história, como ocorria antes da mudança para OA. Essa era uma reivindicação dos alunos surdos após a testagem do AVEA, logo que as narrativas foram implementadas no Moodle. Os Contos, apresentados em português (escrita e áudio) e Libras (vídeo) passaram pela mesma concepção. Cada uma das quatro histórias concebidas também foi isolada, com o diferencial de que outro OA agrega todas elas (Figura 3). Esse OA manteve a interface como um índice, extinguindo a hierarquia originalmente projetada entre o conto principal, ilustrado com imagem animada e com links para as historietas; e os desenhos das historietas em si, menores, que também servem como 'porta de entrada' ao conteúdo. 


\section{$16^{\circ}$ \\ ERGODESIGN USIHC CINAHPA}

$16^{\circ}$ Ergodesign - Congresso Internacional de Ergonomia e Usabilidade de Interfaces Humano Tecnológica: Produto, Informações Ambientes Construídos e Transporte

$16^{\circ}$ USIHC - Congresso Internacional de Ergonomia e Usabilidade de Interfaces Humano Computador

CINAHPA | 2017 - Congresso Internacional de Ambientes Hipermídia para Aprendizagem.

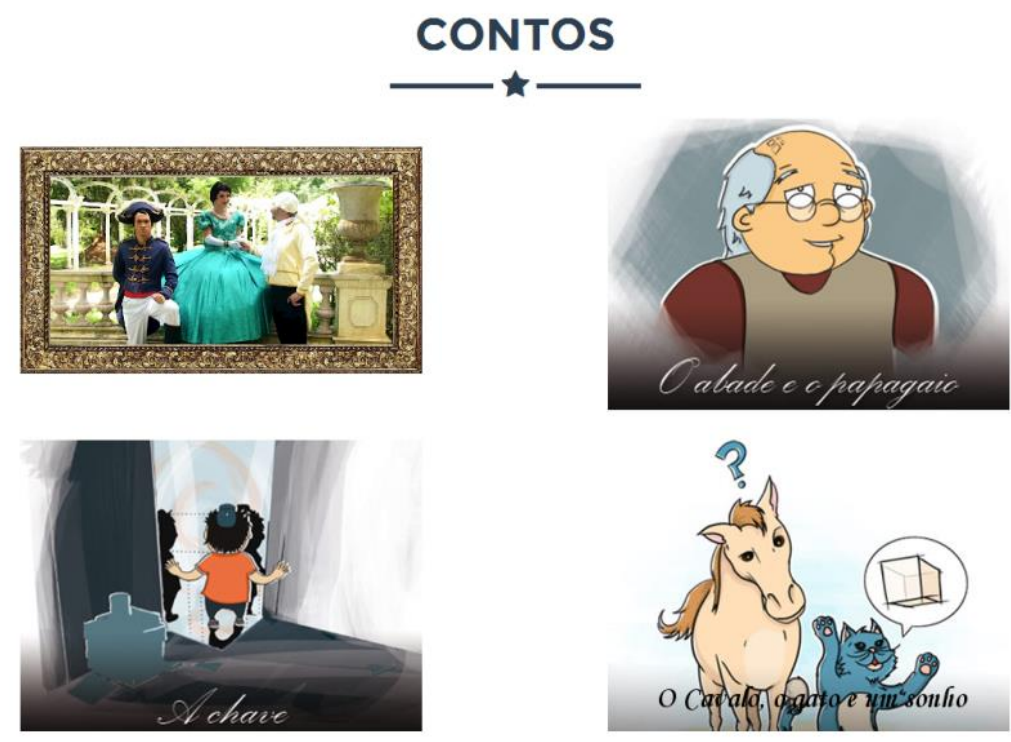

Figura 3: Como coleção, OA oferece os contos de modo independente Fonte: Cognitiva Brasil, 2014

$\mathrm{O}$ primeiro conto, $\mathrm{O}$ enigma de Gaspar (acima e à esquerda na Figura 3), oferece uma imagem elaborada como foto animada, feita com três atores representando Napoleão Bonaparte, Josefine e Gaspar Monge, este último criador das bases fundamentais da GD.

A foto animada foi desenvolvida com objetivo de proporcionar ao usuário uma experiência diferente, uma sensação de revisitar o passado com ilustrações onde os personagens se movem. Para isso contou-se com equipe de gravação de vídeo, diretor e atores, com as locações realizadas no Jardim Botânico do Rio de Janeiro. As poses foram feitas, ensaiadas e repetidas para dar perfeição ao processo. Na edição do vídeo, filtros específicos foram aderidos às imagens que, 'frisadas' no momento exato e posteriormente soltas, dão a ideia de movimento repentino.

Esse conto principal contém links de entrada para três historietas com detalhes técnicos de GD em seus próprios hiperlinks. Elas apresentam uma fábula intitulada $\mathrm{O}$ gato, o cavalo e um sonho; o conto O Abade e o papagaio, simulando um dia de aula do abade Charles de l'Lépée - um símbolo do povo surdo, e o conto A chave, inspirado em história do dramaturgo Oscar Wilde ${ }^{4}$. Cada historieta tem um veio alternativo ao principal, dois finais e atividades para avaliação da aprendizagem. Todos os contos têm hiperlinks que oferecem o conteúdo técnico de GD.

Foram feitas diversas adaptações a fim de permitir que os OAs sejam executados em plataformas móveis como celulares e tablets, além da capacidade de executar em diversos navegadores e sistemas operacionais com o mesmo comportamento. A Figura 4 apresenta um exemplo da captura de uma imagem da HQ em celular.

\footnotetext{
${ }^{4} \mathrm{O}$ conto é inspirado na obra $\mathrm{O}$ retrato de Dorian Gray, de Oscar Wilde.
} 


\section{$16^{\circ}$ \\ ERGODESIGN USIHC CINAHPA}

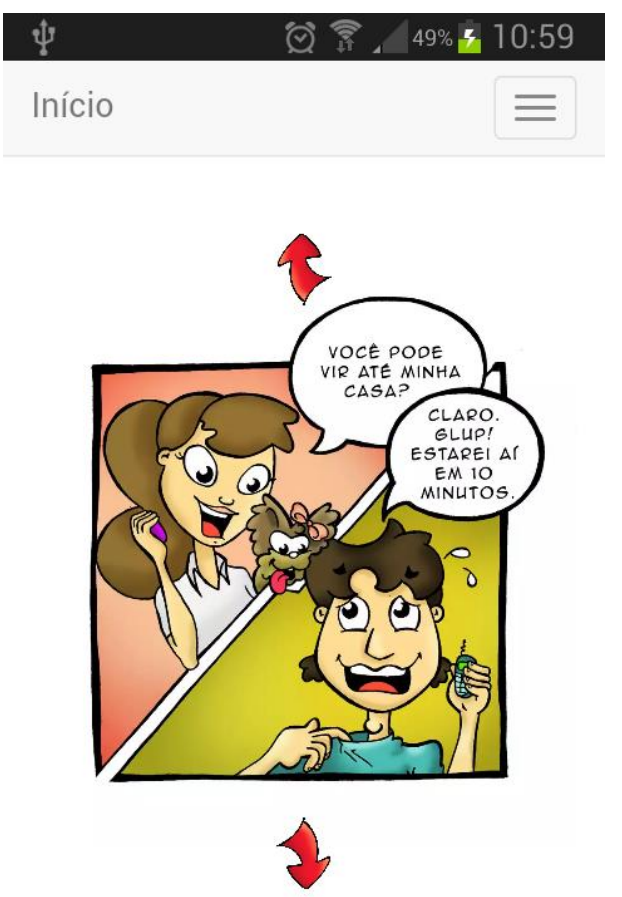

Figura 4 - Captura do OA em quadrinhos executado em um celular

Fonte: Cognitiva Brasil, 2014

O tratamento com o restante do conteúdo (exercícios ilustrados, narrativas dissertativas e infográficos) seguiu o mesmo curso. A testagem dos três primeiros gêneros implementados $-\mathrm{HQ}$, Contos e Narrativa Dissertativa - junto a ouvintes e surdos demonstrou que esta última foi a narrativa preferida para ambos os públicos por ocasião dos testes. Os infográficos foram testados posteriormente, também com surdos, obtendo resultado positivo para seu uso.

\section{Discussão}

Os OAs podem ser definidos como pequenas entidades digitais modulares passíveis de serem utilizadas em diferentes contextos de aprendizagem e acessíveis por meio da internet [WILEY, 2016]. Segundo Wiley [2016], o fato de estarem disponíveis on line oferece outra característica relevante: a possibilidade de acesso e uso simultâneo por um número ilimitado de pessoas. $16^{\circ}$ Ergodesign - Congresso Internacional de Ergonomia e Usabilidade de Interfaces Humano Tecnológica: Produto, Informações Ambientes Construídos e Transporte

$16^{\circ}$ USIHC - Congresso Internacional de Ergonomia e Usabilidade de Interfaces Humano Computador

CINAHPA | 2017 - Congresso Internacional de Ambientes Hipermídia para Aprendizagem.
Tais especificidades colocam os OAs em oposição e vantagem se comparados a outros recursos Longmire [2016] destaca a possibilidade de customização - pois como os OAs devem ser modulares, consequentemente, devem permitir que a recombinação de conteúdos possa acontecer de diferentes formas. $\mathrm{O}$ autor também observa que se esse recurso for projetado a partir de metadados, sua atualização e gestão de conteúdo torna-se mais rápida, permitindo o uso de filtros e mecanismos de seleção e busca.

Filatro [2007] defende que se as possibilidades de adaptação e atualização do conteúdo são facilitadas em OAs e por isso podem estar estreitamente vinculados às necessidades dos alunos, conforme a demanda existente. A autora destaca que, se houver um compartilhamento de iniciativas para diferentes propósitos e contexto, os OAs ainda poderão representar o uso de recursos de baixo custo.

O trabalho de desenvolvimento dos OAs a partir das narrativas em hipermídia implementadas no AVEA WebGD Acessível, do Moodle ao repositório Cognix, por meio do padrão OBAA, buscou manter as recomendações internacionais de acessibilidade para criação de conteúdo on line ${ }^{5}$ já observadas na construção e implementação do ambiente.

De acordo com Macedo [2013], o IMS distingue o conteúdo equivalente do alternativo, definindo como conteúdo equivalente aquele idêntico a outro, porém fornecido em modalidade diferente. Já um conteúdo alternativo, é uma ampliação do conteúdo equivalente e é fornecido de forma diferente, em outra composição, como a que advém dos hiperlinks, por exemplo, porém com o mesmo objetivo final de aprendizagem.

A pesquisa de Macedo [2013] indica uma diretriz principal no trato de OAs: a de que todo conteúdo de um OA deve apresentar pelo menos uma mídia equivalente em formato diferente ou uma mídia alternativa se não for possível uma mídia equivalente. Assim como uma mídia de acesso textual, equivalente ou alternativo. No WebGD

5 World Wide Web - Web Content Accessibility Guidelines (W3C-WCAG) 1.0 (1999), do W3CWCAG 2.0 (2008) e do Institute Management Systems - Global Learning Consortium Accessibility (IMS-GLC-ACC) Guide (2002)
Realização:
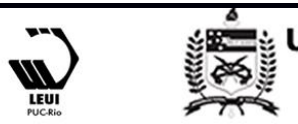
Acessível, predominantemente, as narrativas oferecem o conteúdo nas línguas portuguesa e de sinais; nas linguagens escrita, vídeo, imagens estáticas e áudio.

Seguindo diretriz de Macedo [2013] - de que o áudio deve possuir controle aparente de volume, pausa, liga/desliga, sem som de fundo e opção de mídia textual como: legenda, captions, descrição completa, texto alternativo visual e tradução em Língua de Sinais - é possível ratificar a adequação de todos esses cuidados no AVEA estudado e que foram mantidos nos OAs. Macedo [2013] também recomenda interpretação em Libras se o conteúdo for sonorizado.

Os estudos para o desenvolvimento do WebGD Acessível ressaltam, contudo, que a Libras deve existir em qualquer contexto de inclusão a surdo, não importando se o conteúdo é ou não sonorizado. Verificou-se, igualmente, que o vídeo em Libras exige o mesmo cuidado observado por Macedo [2013] com relação ao áudio, ou seja, o vídeo precisa de controle, pausa, liga/desliga, para que a Libras não ofereça ruído de comunicação ao ouvinte. Daí os OAs conservarem as mesmas características das narrativas em hipermídia implementadas no ambiente.

À Libras deve ser dado lugar de destaque em ambiente inclusivo, pois a pesquisa demonstrou ser este um requisito fundamental de ensino aprendizagem ao povo surdo, tratando-se de um ingrediente da cultura surda e, portanto, poderoso aliado no processo educacional. Diferente para quem tem deficiência auditiva e foi alfabetizado na língua portuguesa, a Libras é a primeira língua (L1) do surdo, enquanto o português surge como L2, independente do resquício de língua oral de cada um.

A necessidade de se considerar a inclusão e a acessibilidade no ensino e aprendizagem a distância advém do fato de que, na EAD, um único curso é capaz de incorporar um número de alunos exponencialmente maior que no ensino presencial. Sendo assim, também contempla uma alta variedade de perfis cognitivos, incluindo, certamente, alunos com diferentes necessidades e especificidades. O desenvolvimento de OAs que conservem as características requeridas pela inclusão aumenta sua importância em ambientes virtuais acessíveis. $16^{\circ}$ Ergodesign - Congresso Internacional de Ergonomia e Usabilidade de Interfaces Humano Tecnológica: Produto, Informações Ambientes Construídos e Transporte

$16^{\circ}$ USIHC - Congresso Internacional de Ergonomia e Usabilidade de Interfaces Humano Computador

CINAHPA | 2017 - Congresso Internacional de Ambientes Hipermídia para Aprendizagem.

\section{Considerações finais}

A evolução das narrativas que compõem o conteúdo do WebGD Acessível da plataforma Moodle para Objetos de Aprendizagem, modelados no padrão OBAA e disponíveis em repositório, conferiu a necessária agilidade que esse tipo de ambiente requer no caso de uso educacional. O uso das narrativas de modo independente, em módulos, com interoperabilidade, possibilidade de recuperação e reusabilidade amplia as possibilidades de ensino aprendizagem em ambientes virtuais para docentes e alunos. No que tange às experiências oriundas do processo de desenvolvimento desse recurso tão específico, ressalta-se e recomenda-se a necessidade de uma equipe interdisciplinar colaborativa, que atue em conjunto de modo planejado e sistemático a partir de uma linguagem comum, com foco no resultado final.

Documentos de especificação como roteiros, storyboards, mapas mentais têm, igualmente, se mostrado determinantes tanto para uma comunicação efetiva entre os integrantes da equipe quanto para o sucesso do resultado final da implementação, diminuindo a margem de erros e a necessidade de alterações e ajustes posteriores. Os vídeos em língua de sinais e os hiperlinks com explicações para os termos técnicos em GD, no caso do WebGD Acessível, revelam-se ferramentas promissoras no sentido do favorecimento da aprendizagem dos públicos alvos pesquisados: alunos sem deficiência e com deficiência auditiva e visual. AVEAS inclusivos bilíngues e com explosão de linguagens favorecem o cumprimento da perspectiva de uma verdadeira inclusão, um ponto a mais para a diversidade da vida.

\section{BIBLIOGRAFIA}

\section{FILATRO, A. Design instrucional}

contextualizado: educação e tecnologia. 2. ed. São

Paulo: Ed. SENAC, 2007.

IEEE - LTSC. The Learning Object Metadata

Standard Retrieved. IEEE - LTSC - Learning

Technology Standards Commitee Web Site, 2010.

Disponível em: <http://www.ieeeltsc.org:8080/
Realização:

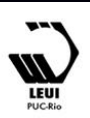




\section{$16^{\circ}$}

ERGODESIGN USIHC CINAHPA $16^{\circ}$ Ergodesign - Congresso Internacional de Ergonomia e Usabilidade de Interfaces Humano Tecnológica: Produto, Informações Ambientes Construídos e Transporte

$16^{\circ}$ USIHC - Congresso Internacional de Ergonomia e Usabilidade de Interfaces Humano Computador

CINAHPA | 2017 - Congresso Internacional de Ambientes Hipermídia para Aprendizagem. /working-group/learning-object-metadata-workinggroup-12/learning-object-metadata- lom-workinggroup-12>. Acessado em nov. 2016.

IMS - GLC - ACC. (2002). Guidelines for Developing Accessible Learning Applications V.1 White Paper. IMS Global Learning Consortium Inc., 2002. Disponível em:

<http://www.imsglobal.org/accessibility/>. Acesso em nov. 2016.

LONGMIRE, W. A Primer on Learning Objects. ASTD's Source for e-learning, 2000. Disponível em:

<http://www.astd.org/LC/2000/0300_longmire.htm $>$. Acesso em set.2016.

MACEDO, C.M.S. de Diretrizes de acessibilidade em conteúdos didáticos. Revista Brasileira de Design da Informação. Infodesign. V.10, n.2, 2013, p.123-136.

POMERANTZ, J. Metadata: Organizing and discovering information. Disponível em https://www.coursetalk.com/providers/coursera/co urses/metadata-organizing-and-discoveringinformation. Acesso em maio 2016.
ROSSI, L.H.L. Relatório Cognitiva Brasil. Desenvolvimento e catalogação de objetos de Aprendizagem. UFRGS, 2014. ROSSI, L.H.L. et al. A Federated Retrieval System for Learning Objects. Procs of International Conference on Internet Technology and Applications, 2012, Wuhan. Proceedings of iTAP (2012).

SANTOS, L. FLORES, M.; TAROUCO, L. Objeto de Aprendizagem: Teoria Instrutiva Apoiada por Computador. Novas Tecnologias na Educação. Porto Alegre: CINTED-UFRGS, 2007. VICARI, R. et al. The OBAA Proposal for Learning Objects Supported by Agents, Procs. of MASEIE Workshop-AAMAS 2010. 2010. WILEY, D. A. Connecting learning objects to instructional design theory: A definition, a metaphor, and a taxonomy. 2000. In: WILEY, D. A. (Ed.). The Instructional Use of Learning Objects: Online Version. Disponível em: <http://reusability.org/read/chapters/wiley.doc >. Acesso em set. 2016.

Agradecimentos à CAPES e ao CNPq pelo apoio a esta pesquisa. 